\title{
A Psicologia Social no Estudo de Justificativas e Narrativas de Homens Autores de Violência
}

\author{
Ana Luíza Casasanta Garcia ${ }^{1}$ \\ ${ }^{1}$ Universidade Federal de Santa Catarina, SC, Brasil. \\ Adriano Beiras ${ }^{2}$ \\ ${ }^{2}$ Universidade Federal de Santa Catarina, SC, Brasil.
}

Resumo: Considerando que a Psicologia Social auxilia para que práticas e ações sociais sejam problematizadas, este estudo tem como objetivo evidenciar como os sentidos de si e do Outro identificados em narrativas de homens autores de violência sustentam e justificam a ação violenta cometida. Para tal, quatro narrativas de homens participantes de um grupo reflexivo de autores de violência em uma cidade do sul do Brasil foram utilizadas e analisadas por meio da análise temática das narrativas. Os resultados revelaram que os homens, depositaram a justificativa da sua "agressividade" em um Outro. E este Outro, por muitas vezes, pôde ser identificado como uma referência aos vínculos sociais e aos sentidos do ser homem. Foi possível constatar que o modo como os sujeitos percebem suas trajetórias de vida, permeadas pelas experiências de resistência e construção frente a um contexto onde, segundo eles, havia falta de carinho, agressividade e ausência, sobretudo, paterna, parece construir um cenário propício para a emersão da violência. A partir disso, ressalta-se a importância que os participantes dão aos vínculos significativos sociais e à dicotomia do ser homem/ser mulher, bem como à forma pela qual essa dinâmica relacional mergulha em preceitos e valores éticos e morais. Isto, por sua vez, leva-nos a pensar como o olhar da Psicologia Social Crítica auxilia para que problemáticas sociais sejam identificadas e postas à tona, assim como outros modos de existência tanto para homens como mulheres possam emergir e ser visibilizados. Desta forma, problematizando gênero, seja possível a reconstrução e transformação social.

Palavras-chave: Violência contra mulheres, Homens autores de violência, Narrativas, Relato de si, Relato do Outro.

\section{Social Psychology in the Study of Justifications and Narratives of Men who Commit Violence}

\begin{abstract}
Considering that Social Psychology assists so that social practices and actions can be problematized, this study aims to show how the senses of the self and the Other identified in narratives of men who commit violence sustain and justify their violent actions. To that end, four narratives of men who participated in a reflective group of men who committed violence in a city in southern Brazil were used and analyzed through the thematic analysis of the narratives. The results revealed that men justified their "aggressiveness" in the Other. And this Other, for many times, could be identified as a reference to the social bonds and the senses of the human being. It was possible to verify that the way in which the individuals perceive their life trajectories, permeated by the experiences of resistance and construction before a context where, according to them, there was a lack of affection, aggression and absence, especially, paternal, seemed to construct a scenario conducive to the emergence of violence. From this, it is highlighted the importance that the participants give to the significant social bonds and to the dichotomy of being male/female, as well as to the way in which this relational dynamic plunge into ethical and moral precepts and values. This, in turn, leads us to think how the look of Critical Social Psychology helps social problems to be identified and raised, just as other modes of existence for both men and women can emerge and be seen. In this way, problematizing gender makes possible to reconstruct and socially transform.
\end{abstract}

Keywords: Violence against women, Men who commit violence, Narratives, Self-report, Report of the Other. 


\title{
La Psicología Social en el Estudio de Justificativas y Narrativas de Hombres Autores de Violencia
}

\begin{abstract}
Resumen: Teniendo en cuenta que la psicología social ayuda a problematizar las prácticas y acciones sociales, este estudio tiene como objetivo resaltar cómo los sentidos de uno mismo y del Otro identificados en las narraciones de los autores de violencia masculinos sostienen y justifican la acción violenta cometida. Con este fin, se utilizaron y analizaron cuatro narrativas de hombres que participaban en un grupo reflexivo de perpetradores de violencia en una ciudad del sur de Brasil a través del análisis temático de las narrativas. Los resultados revelaron que los hombres depositaron la justificación de su "agresividad" en un Otro. Y este Otro, muchas veces, podría identificarse como una referencia a los lazos sociales y los sentidos del ser humano. Fue posible verificar que la forma en que los sujetos perciben sus trayectorias de vida, impregnada por las experiencias de resistencia y construcción que enfrentan en un contexto donde, según ellos, había falta de afecto, agresión y, sobre todo, ausencia paterna, parecían construir un escenario favorable para el surgimiento de la violencia. A partir de esto, se enfatiza la importancia que los participantes le dan a los lazos sociales significativos y la dicotomía de ser hombre/ser mujer, así como la forma en que esta dinámica relacional se sumerge en preceptos y valores éticos y morales. Esto, a su vez, nos lleva a preguntarnos cómo el aspecto de la Psicología Social Crítica ayuda a identificar los problemas sociales y los trae a la luz, así como también otros modos de existencia para que hombres y mujeres emerjan y se hagan visibles. Así, problematizando el género, sea posible la reconstrucción y transformación social.
\end{abstract}

Palabras clave: Violencia contra la mujer, Hombres autores de violencia, Narrativas, Autoinforme, Informe del Otro .

A compreensão dos mecanismos que justificam práticas violentas e o olhar sobre aqueles que agridem têm se tornado ângulos importantes de estudo e análise para entendermos melhor as relações violentas e aprimorar ações de políticas públicas, para além de ações separadas entre vítimas e agressores. Tivemos muitos avanços sociais e legislativos, porém, na prática e na teoria, são necessários avançar e problematizar ações de forma a aprofundar nosso entendimento sobre o fenômeno dos conflitos violentos conjugais.

Empenhada nesta tarefa de discutir, debater e criar conhecimentos sobre as conjunturas que circundam as demandas sociais, a Psicologia Social tem se demonstrado como uma importante área para a produção de estudos sobre as violências. Mas, de que forma a Psicologia Social e suas interfaces interdisciplinares auxiliam neste campo de estudo? Que conceitos ainda pouco explorados nos ajudariam a lançar outros olhares para o tema?

Buscando pensar sobre como a Psicologia pode lançar ações e políticas sociais diversas que auxiliem na ruptura de práticas violentas e desvelam seus mecanismos complexos e bases que as mantém em nossa sociedade, e considerando que, em um tempo em que moralidades passam a ser tema político e discursivo de movimentos conservadores, precisamos também problematizar estas categorias desde as epistemologias da Psicologia Social e refletir sobre seus impactos sociais. Provocados por J. Butler, somos levamos a pensar que vidas e modos de vida não são vistos e que lutas diversas transversais precisam ser problematizadas para pensarmos e olharmos diferentes ângulos de acesso e para as violências.

Pensando dessa forma, entendemos, em primeiro lugar, que a Psicologia Social e seu olhar epistemológico direcionam-se para uma análise que faz pensar em possibilidades de rupturas ou manutenção de práticas violentas. Neste sentido, buscando problematizar de que forma a Psicologia Social contribuiu para que pensássemos a respeito das dinâmicas sociais que sustentam, intensificam e/ou contribuem para o surgimento da violência contra as mulheres, traremos adiante narrativas de homens autores de violência que nos fazem problematizar para além do 
empírico, trazendo as contribuições do olhar da Psicologia social para estudos e intervenções em prol do enfrentamento das práticas e discursos de violência.

Primeiramente, aponta-se que a violência contra as mulheres perpassa questões macromorais e éticas, e está intimamente ligada ao modo como o gênero foi socialmente, discursivamente e culturalmente construído. Sobre ética, ético, boa postura, conduta adequada, diversas são as terminologias utilizadas para se definir o que vem a ser a ética e a moralidade, termos tão raros para a ciência tradicional, mas que têm sido tão comuns e discutidos no senso comum e também religioso e político. Sobre a origem destas termologias, a Ética vem do grego, ethos e significa: "o modo de ser, o caráter" (Motta, 1984). E Moral vem de Morales e faz inferência ao significado de "costume" de uma cultura (Motta, 1984). Entretanto, assim como sinalizado por Pedro (2014), apesar da divergência de significados, há uma forte relação e articulação entre estes dois termos, na medida em que a ética tem como principal objetivo o estudo da moral.

Nesse sentido, tem-se uma relação dialética entre o construto da ética e o constructo da moral e, nessa relação, é possível observar algumas implicações como, por exemplo, a forma pela qual a moral implica a ética para se repensar e como a ética é construída pela moral vigente (Pedro, 2014).

Essa dinâmica relacional, por sua vez, nos leva a pensar que, se algo é ético ou moralmente aceito, este algo está se comportando ou se apresentando da forma como se espera que ele se comporte ou aja. Percebemos também que ninguém "nasce sendo ético" ou "nasce praticando os valores morais", esse predicado só é atribuído aos verbos quando os sujeitos da frase se alocam em uma cultura e em um contexto histórico e é atravessado por diversas categorias que lhe dirão o que é "ser ético" e o que são os "valores morais" daquela sociedade específica (Butler, 2015; Fassin, 2014). Falar de ética e moral, portanto, é falar de modos de ser de uma sociedade. É falar de como aquela sociedade, em específico, funciona, se mantém, se articula e se relaciona. É falar, portanto, de política, de normalização e de processo de subjetivação dos sujeitos.

Entende-se, dessa forma, que a construção localizada de valores morais e éticos ocasiona consequências no modo de viver e de se compreender o mundo a depender da história, da sociedade e da temporalidade em que nos referimos. Nesse sentido, é possível pensar que as emoções, a vivência e os valores individuais dos sujeitos também se imbricam nestas conexões de valores e normas.

O antropólogo francês Fassin (2005), com a implementação do conceito de "economia moral", auxilia-nos na compreensão de como a moralidade e a ética em uma sociedade tangencia um "modo de funcionamento social". Com esta reflexão, entende-se como economia moral, o fenômeno continuamente recomposto segundo as normas e limites historicamente constituídos dentro de uma dimensão política, social e histórica (Fassin, 2005).

Para explicar este conceito melhor, retomemos o exemplo que o próprio Fassin (2014) aborda em um artigo escrito por ele e que discorre a respeito do processo de imigração de centenas de imigrantes de Kosovo, Curdistão e Afeganistão que estavam fugindo da opressão em busca de asilo na Grã-Bretanha. A partir da análise deste processo, Fassin (2014) aponta que o corpo em sofrimento parece ter mais legitimidade do que um corpo ameaçado. Isso quer dizer que, perpassado por paixões, normas, sentimentos e estereótipos, é mais aceitável ao Estado rejeitar um pedido de asilo do que ir contra uma perícia médica de um corpo que clama cuidados de saúde (Fassin, 2014). Vemos, dessa forma, que há ética e valores morais envolvidos nesta distinção. O sofrimento, aqui, parece ter mais legitimidade, por retratar um sentido de humanidade comum coletivamente expressa por meio da atenção prestada às necessidades humanas (Fassin, 2014).

Outro caso em que também podemos pensar em premissas éticas e morais é o polêmico caso que envolveu o ator José Mayer, em abril de 2017. Nesta data, a figurinista Susllem Tonani denunciou José Mayer por assédio sexual, tanto por intermédio de palavreado impróprio, como por toque em partes íntimas, sem o consentimento da figurinista. Envolvendo um ator da Rede Globo, os holofotes e a mídia não iriam deixar de produzir de diversos conteúdos sobre o assunto. Assim, manchetes, fofocas, especulações e comentários fizeram parte desta cena questionando o comportamento de José Mayer. Neste sentindo, comentários do tipo: "Pra ser mau/caráter, basta ser homem!", "Mexeu com uma mexeu com todas!", "Agora, a gente fica até com medo de fazer um elogio, encostar. Não dá para fazer nada" são algumas das frases que podemos encontrar nos websites. E que reflexões podemos fazer frente a estas frases? Por que um homem é comparado com o mau-caratismo? Por 
que o assédio relatado pela figurinista foi comparado a um elogio? Será que há ética e valores morais na produção de tais falas?

Pensando sobre estas perguntas e com os exemplos acima, é possível pensar sobre esse "senso de justiça" que pareceu mover milhares de internautas frente ao caso de José Mayer e que muito se relaciona com o "pensamento moralmente aceito" discorrido nos exemplos anteriores. Este senso, a saber, se refere ao que Adorno (2001) irá chamar de ethos coletivo. O ethos coletivo, trazido pelo pensador da escola de Frankfurt, se refere a uma "unidade", totalmente questionável, que, agindo de forma conservadora, representa o pensamento "universal" de uma sociedade, ou seja, uma normalidade esperada. Por normalidade, entende-se tanto como uma expectativa biomédica de padrão de funcionamento da espécie quanto um preceito moral de produtividade e adequação às normas sociais. Que, segundo Foucault (2001), se opõe à irregularidade, à desordem, à esquisitice, à excentricidade, ao desnivelamento, à discrepância e, de outro lado, à norma ancorada na medicina orgânica ou funcional, à norma como regularidade funcional, como princípio de funcionamento adaptado e ajustado; o "normal" a que se oporá o patológico, o mórbido, o desorganizado, a disfunção (Foucault, 2001, p. 204).

Assim sendo, a norma, a normalidade, o ethos coletivo podem ser entendidos como regras de conduta e regularidade funcional social, que se opõem ao que é considerado desordem e irregularidade e disseminado pelo poder de normalização (Adorno, 2001; Foucault, 2001). O poder de normalização, a saber, a maneira como ele se formou, a maneira como se instalou, segundo Foucault (2001), "se deu sem jamais se apoiar numa só instituição, mas se deu através do jogo que conseguiu estabelecer entre diferentes instituições" (p. 31). As instituições se constituíram, portanto, como instâncias de controle do anormal e é isso que transforma a norma, segundo o autor, como um importante problema teórico e político.

Retomando os exemplos dados, pensemos: por intermédio das instituições sociais devidamente localizadas sócio-historicamente, o modo de agir de um sistema feudal, o modo de ser do brasileiro, o preconceito aos negros e o modo de pensar sobre o caso do ator José Mayer foram construídos socialmente e construíram sujeitos inteligíveis que pensaram sobre cada situação (Guanaes-Lorenzi, Moscheta, Corradi Webster, \& Souza, 2014). Desta forma, a Família, o
Estado, a Escola e a Igreja fazem parte deste leque de instituições que disseminam normas e constroem sujeitos a depender de preceitos dicotômicos de "certo" e "errado" presentes na sociedade.

Se falamos de sociedade, estamos falando de pessoas, de corpos, de sujeitos. Neste sentido, falamos de "eus" que se "subjetivizam" frente aos valores morais e éticos de uma sociedade, interiorizando normas e disseminando pensamentos. Estes "eus", mergulhados em um contexto específico, falam não só deles, mas de tudo e de todos que os constroem. Falam de suas políticas de localização. Falam de seus corpos biopolíticos (Foucault, 2001). Os sujeitos, então, não são unificados, mas sim fragmentos, composto de imagens e eventos desintegrados.

Fragmentados e desintegrados, os "eus" quando não estão de acordo com as normas morais, deliberam, por intermédio da linguagem (Spink, 2010), sobre normas e esta liberação ocasiona uma compreensão crítica de sua gênese social e de seu significado (Butler, 2015). O "si mesmo", neste processo, se constroem constantemente e a linguagem se torna crucial para a elaboração dos sujeitos (Gergen, 1985).

E como um sujeito pode narrar a si mesmo? $\mathrm{O}$ que seria o "si mesmo" se somos resultados de um conjunto de atravessamentos sociais que o constrói (constantemente)? (Guanaes-Lorenzi et al., 2014). Percebemos, então, que o sujeito não pode narrar a si mesmo sem se responsabilizar-se e que esta responsabilidade não está alheia às condições sociais em que está inserido (Butler, 2015). Além disso, percebemos que o narrar, o falar de si é uma tarefa sem fim. Sem fim pois, ao falar de mim, falo de tudo que constrói e, nesse processo, não sei o que é meu e o que é da sociedade que molda. Ou seja, não sabemos o que são interesses particulares e os interesses universais, visto que "não somos simples díades independentes, uma vez que nossa troca é condicionada e mediada pelas convenções, pela sedimentação das normas que são de caráter social e que excedem a perspectiva daqueles envolvidos na troca" (Butler, 2015).

A moralidade e a ética, nesse sentido, inserem-se no entre o eu e o mundo (Butler, 2015). Ou seja, ela se insere na relação entre o eu e o mundo que, imersa sob um tecido social específico, se mantêm de forma dialética: o "eu" se constrói pela sociedade e a sociedade é formada pelos "eus" que também deliberam valores morais e princípios éticos a depender de um contexto histórico e cultural específico. 
"Incompletos", somos sujeitos sociais que performatizam práticas morais, definindo uma posição em relação ao que fomos construídos a respeitar e estabelecendo para nós um certo modo de ser que vale como uma realização moral de nós mesmos (Foucault, 1990; Guanaes- Lorenzi et al., 2014). Esta realização, a saber, só encontra sentido por intermédio do reconhecimento. Para entendermos melhor sobre o termo reconhecimento, convido dois outros autores importantes: Axel Honneth e a feminista Nancy Fraser.

Baseando-se na teoria hegeliana, Honneth elabora a obra Luta por reconhecimento: a gramática moral dos conflitos sociais (2003), que teve como tema central defender a ideia de que os sujeitos e os grupos sociais se inserem na sociedade por meio de uma luta por reconhecimento intersubjetivo e não somente pela autoconservação, como é dito nos escritos de Maquiavel e Hobbes. Tal reconhecimento, segundo este autor, se manifesta em diferentes dimensões da vida, como no amor, nas relações jurídicas e na esfera da solidariedade social. Para cada forma de reconhecimento há uma autorrelação prática do sujeito (autoconfiança nas relações amorosas e de amizade, autorrespeito nas relações jurídicas e autoestima na comunidade social de valores). E, se há um desrespeito mediante estas autocorrelações, haverão, segundo Honneth, lutas sociais (2003).

Fraser (2007), por sua vez, integra o reconhecimento com a redistribuição, defendendo a tese de que a luta por reconhecimento é a luta dos grupos marginalizados, transversalizados pela nacionalidade, etnicidade, raça, gênero e sexualidade. Nesse sentido, essa luta reivindica a justiça social por meio de dois tipos: pela ordem redistributiva que defende a busca por distribuição de renda e de recursos e pelas chamadas "políticas de reconhecimento" que lutam em prol de um mundo mais igualitário e justo, que trata amistosamente as diferenças. É visto, dessa forma, que tanto Fraser (2007) como Honneth (2003) apontam em suas teorias a ideia de que a categoria do reconhecimento estaria ligada às lutas sociais contemporâneas, teorizando, assim, sobre os padrões de justiça presentes na sociedade capitalista (Ferreira, 2010).

Neste sentido, podemos pensar que os sujeitos buscam ser reconhecidos e este processo só se realiza pelo olhar de um Outro externo ao sujeito. Este olhar, por sua vez, reconhece e despossui. Despossui na medida em que causa vulnerabilidade e insegurança social e civil frente ao (não) reconhecimento do sistema individual do sujeito (Butler, 2015). Para além disso, o próprio sujeito, considerando o fato de que ele é formado por um conjunto de convenções sociais e por formas de racionalidade que o torna inteligível (Butler, 2015), se despossui, por não conseguir distinguir o que é seu, do outro e do meio em que se insere.

Partindo desse entendimento, compreende-se que a desigualdade de gênero, entendida como uma diferença simbólica em se ter nascido com vagina ou pênis, foi socialmente e culturalmente construída, moldando valores morais e éticos baseando-se nela (Butler, 2015; Perea, 2003). Esta conjuntura, por sua vez, arquiteta também um terreno propício para o surgimento da violência contra as mulheres (Butler, 2003).

A violência contra as mulheres, permeando por entre o âmbito público e âmbito privado, configura-se como um problema de segurança e de saúde pública. A respeito do âmbito privado, embora seja difícil quantificar o número real de mulheres que sofrem algum tipo de violência, em razão da ausência de denúncia e pelo fato de que muitas das vezes as mulheres são agredidas dentro de suas próprias casas (Villela, \& Lago, 2007), estima-se que cerca de $65 \%$ das mulheres agredidas sofrem a violência pelo próprio parceiro de relacionamento. Maridos, companheiros, namorados, bem como ex-maridos, ex-namorados ou ex-companheiros se tornam, então, os atores principais no cenário da violência (Brasil, 2010).

Sobre o âmbito público, um bom exemplo a ser citado se pauta na análise da condição social e econômica da população feminina. Ainda hoje, conforme pesquisa realizada em 2009 pelo Banco Interamericano de Desenvolvimento (BID), mulheres ganham cerca de $30 \%$ menos que os homens desempenhando as mesmas tarefas. Este aspecto, para além de ser uma desigualdade social baseada na desigualdade de gênero, também causa consequências na relação conjugal, propiciando conflitos (Carneiro, \& Oliveira, 2008).

Percebemos, portanto, que, tanto a "diferença" sexual socialmente construída como a relação de dominação masculina e sujeição feminina são categorias/constructos que manejam um terreno fértil para o aparecimento de violências. Ainda, a genitália, o corpo, aqui se tornam instrumentos justificáveis para uma opressão/dominação. Ter uma vagina ou ter um pênis deveria ser uma justificativa para ser um corpo mais bem-aceito e respeitado em uma sociedade? Até 
que ponto a ontologia do corpo é articulada com uma ontologia social? Quais preceitos, razões, sentidos beneficiam certos corpos em detrimento de outros?

Frente a estas questões, este escrito procura problematizar e lançar outros modos de produzir conhecimento na Psicologia, repensando epistemologias, territorialidades e marcadores sociais. A partir do empírico, convidamos a pensar a produção de outras epistemologias na Psicologia Social, com teor crítico, político e reflexivo, para fundamentar a intervenção social com estes sujeitos. Para tanto, a parte empírica do estudo analisa narrativas de homens autores de violência, evidenciando os sentidos de si e do Outro identificados em narrativas de homens autores de violência e como estes sentidos formados culturalmente e socialmente sustentam e justificam a ação violenta cometida. Convidamos a pensar uma Psicologia que se implica ao panorama social amplo e a partir disso possa repensar e aprimorar polícias públicas neste setor, atentos a cada momento histórico, político e social amplo como marcadores importantes e conectados ao subjetivo e intersubjetivo na produção relacional e conjugal. Ainda, com este movimento, almejou-se evidenciar como a problematização sobre estes temas se tornam uma aposta que a Psicologia pode para a aproximação com ações de ruptura de práticas violentas, com as lutas transversais, de investimento nas vidas que ninguém vê. Mas que vidas são estas? Que modos de existir são permitidos e como, analisando a produção de modos hegemônicos, conseguimos entender melhor aqueles modos e vivências excluídos na construção de experiências e processos de subjetivação possíveis?

\section{Metodologia}

Baseando-se na metodologia de análise temática das narrativas, esta pesquisa se ancorou nas narrativas produzidas por quatro homens participantes de um grupo reflexivo de autores de violência em uma cidade do Sul do Brasil. Com nomes fictícios, a fim de preservar o anonimato dos participantes, os dados dos sujeitos são demonstrados pela Tabela.

\section{Análise das informações}

Organizados e analisados os dados com o auxílio do software Atlas/ti 8.0 e baseando-se na Teoria Fundamentada (Grounded Theory), as narrativas dos homens autores de violência foram analisadas com o intuito de entender como a visão de mundo foi construída pelo sujeito, ou em outras palavras, como os valores morais, a ética sustentam e justificam a ação violenta cometida pelos participantes baseando-se na concepção de si e do Outro. Dessa forma, a fim de apresentar as informações adquiridas, apresentarei os tópicos: a) o relato de si; b) o relato do outro.

\section{$O$ relato de si}

Em meio a julgamentos e percepções oriundos do Outro (Butler, 2015), percebe-se que, muitas das vezes, apresentamos o "melhor de nós", reafirmando o ditado popular "é a primeira impressão que fica". Seguindo esta linha de raciocínio, percebeu-se, de antemão, que, ao iniciar o relato sobre si e sobre sua trajetória de vida, os sujeitos, em algum momento, justificaram o "porquê" estarem participando do grupo e ser visto pelo Outro como alguém "agressivo", "violento". É curioso que eles trouxeram essas informações sem antes terem sido interpelados para fazerem este relato. Parecia que eles sentiam a necessidade de se justificar pelo ato e de fazerem jus à premissa de que "nossas histórias pessoais são produtos de nossos engajamentos em relacionamentos e em diálogo" (Martins, Mcnamee, \& Guanaes-Lorenzi, 2014, p. 21). Ainda, podemos pensar que estas falas, estas justificativas seriam, talvez, uma "Luta por reconhecimento" (Honneth, 2003), movimento em prol de não serem reconhecidos por serem "violentos", "agressivos".

Tabela

Dados dos participantes.

\begin{tabular}{lcccc}
\hline Participante & Naturalidade & Estado civil & Grau de escolaridade & Idade \\
\hline Rogério & Santa Catarina & Separado & Ensino fundamental completo & 44 \\
Frederico & Santa Catarina & Separado & Ensino fundamental completo & 44 \\
Mário & Santa Catarina & Separado & Ensino fundamental incompleto & 53 \\
Oswaldo & Santa Catarina & Casado & Ensino fundamental incompleto & 43 \\
\hline
\end{tabular}


Sobre a figura de homem associada ao "macho", à valentia, virilidade e controle sobre as mulheres (Ramirez Rodríguez, \& Vázquez, 2008) também pode ser traçada na narrativa de Rogério. Em sua entrevista, Rogério diz que existem vários tipos de homem, mas ele destaca o homem-cabeça e o homem-calda, o homem que rasteja. Para ele, o homem-cabeça:

é o homem de posição. É o homem que vai gerar emprego, ele vai gerar coisas, vai gerar negócio em volta dele. Homem que sobressai. Homem que vai ta merecendo toda a vida a mulher. $\mathrm{E}$ o homem que rasteja é o homem que não vai crescer nunca na vida. Isso já é a realidade.

Em outro momento, Rogério diz que o homem-cabeça é o homem sério. Segundo ele,

Tem o homem meloso, que é o homem que vai dando flores pra mulher, fazendo isso, fazendo aquilo, mas na hora que pega pra casar, pula fora. E tem o homem sério que é o homem real, ele vive no tempo real. Ele chega e fala, de cima embaixo, entende? Porque hoje em dia, nós vivemos com de mulher em épocas diferentes. O que é época diferente? Eu já tive uma enteada, já criei. Tá casada hoje, chegou um certo tempo, tava a famosa calça colada, eu não sei como se chama aquilo lá. Mas você olha pra aquilo lá não enxerga a mulher, enxerga só o negócio. [...] e eu reeprendi, porque. A mulher pra ela ser bonita, pra ser uma mulher mesmo maravilhosa, ela não precisa detalhar o corpo na rua pra todo mundo ver.

Percebeu-se que, para Rogério, sendo "um homem-cabeça", "um homem sério", é sua função "proteger", "olhar de cima-embaixo" o comportamento da mulher, pois assim, preserva-se sua masculinidade, sua virilidade e seu controle sobre as mulheres (Ramirez Rodríguez, \& Vázquez, 2008). Adotando essa postura de "macho", "provedor", "supervisor" em vários trechos da entrevista, Rogério também não se enxerga como um homem violento. Para ele, ele foi acusado injustamente e o que fez foi em prol da proteção de seus filhos. Nas palavras de Rogério:

só que nem eu to falando pra ti, eu to aqui porque houve um episódio que nem eu to falando pra ti, eu to sendo acusado, automaticamente por uma situação que eu não fiz. Porque se eu tivesse batido, agredido, mesmo, eu teria o maior prazer em pagar. Até isso te comentei. Só que hoje eu to aqui pra defender meus filhos. E eu não vou mover mais nenhuma palha porque minha cabeça tá em paz, meu coração tá em paz, fiz tudo que foi possível. Agora as pessoas da alta... da lei jurídica tão conhecendo os fatos. Entende? Porque se eu fosse um cara bandido, fosse um cara agressivo, minhas mãos não eram calejadas. Você tá falando com um homem que veio da roça, que veio do mato. Um homem que teve princípios na educação.

Percebe-se, novamente, que, em primeiro lugar, o entrevistado justifica a ação violenta, sem antes ter sido questionado a respeito. Este movimento, a saber, pode ser interpretado como uma reafirmação de que Rogério não se considera um homem violento, nem agressivo. Afinal, as mãos calejadas não são de "homem-bandido", "homem-agressivo". Além disso, pela narrativa da mão calejadas e de sua trajetória de vida, também é possível pensar a respeito da luta pelo reconhecimento do Outro, utilizando como instrumento principal uma narrativa que enfatiza momentos difíceis, emoções, sentimentos e sofrimento para retratar mais legitimidade (Fassin, 2014; Honneth, 2003).

Na entrevista de Oswaldo, por sua vez, percebe-se que o entrevistado, ao falar de si, narra sobre sua jornada de trabalho, remetendo a ideia de que ele sempre fora um homem trabalhador, provedor. Nas palavras dele,

Eu sou um cara madrugador... desde do sítio, na época cuidar da bicharada, sabe. Dai eu saio de madrugada. Dai era 4 hora, 3 e meio eu já tava no trabalho, ensinando as vaca, alimentando a porcada, tratando a ração, os bois, fazendo o serviço, as vezes o cara tem aquilo ali... só que nunca me pesou né, esse serviço...

Sobre esta colocação ainda cabe ressaltar sobre como Oswaldo posiciona seu "poder" de ter conquistado coisas materiais nas brigas com sua ex-esposa. Segundo relato da briga que causara a denúncia de violência, Oswaldo discorre:

dai bota um cd novo que eu comprei. Ai botou né. Tava escutando, dai a pouco ela veio com as 
criança lá né. E, quase enlouqueceu, veio lá, já mandou eu ficar quieto, já. E mandou eu desligar, não sabia as música né. Cala boca, manda nada. Parece que tava com o diabo no corpo. E como que não manda? Essa casa é minha! Ta tudo no meu nome. Eu não vou mandar? Né. Dai começou a berrar comigo né. Tao ta eu não mando nada então, vou pegar e procurar meus direito né. Dai começou a botar minhas coisas pra fora. Logo lá fora. Ai sabe, peguei minha roupa. Você sabe. Você contra eu. Ai aquele tipo de mãe né. Você sabe. Aquelas mulher barraqueira, que gosta de berrar, gritar, faz ta pronto.

A partir destes trechos da entrevista de Oswaldo, pode-se pensar sobre como o entrevistado enfatiza e expõe sua masculinidade, em prol de ser reconhecido como um homem com "H" maiúsculo. Assim como apontado por Beiras (2008), as masculinidades se correlacionam com outros âmbitos presentes na nossa sociedade, tais como o trabalho, o tecido social, a família, a sexualidade, a homofobia, a globalização, a corporeidade etc. Frente ao exposto, entende-se que para se analisar a subjetividade masculina, é necessário estar atento e levar em consideração a micro e macroinfluência que estes âmbitos possuem na construção social da subjetividade do homem (Beiras, 2008).

No caso do trabalho e da economia, percebe-se que o reconhecimento do "ser homem" é tangenciado por uma configuração de "ser provedor", aquele que possui, também através do poder aquisitivo "a ascendência alcançada através da cultura, das instituições e da persuasão" (Connell, \& Messerschmidt, 2013, p. 245). Através da narrativa de Oswaldo, ele é quem manda, pois "a casa é dele e tudo está em seu nome". Frente a isso, ele tem o poder de controle sobre a estrutura doméstica e sobre sua esposa.

Ainda a respeito das tramas narrativas apresentadas por Oswaldo, dá-se atenção à frase "Eu pegava das 5 da manhã até as 10, 11 horas da noite. Então depois eu comprei casa, comprei tudo". Destaco-a por ela representar dois pontos importantes: um sobre a questão da performatização da miséria e outro sobre a questão da meritocracia. Dessa forma, para discorrer a respeito do primeiro ponto, trago novamente Fassin (2014). No relato de Oswaldo, há a especificação dos horários exaustivos de jornada trabalho, para enfatizar a quantidade de horas trabalhadas por dia para, então, conseguir comprar "tudo".
Vemos que Oswaldo assim como Mário que retratou sobre suas mãos calejadas performatizaram, por meio de argumentos morais, o sofrimento do labor, da dificuldade de terem construído e conquistado as coisas que possuem hoje. Colocando o corpo como fonte de direitos e de sinais de incorporação do poder pelos dominados (Fassin, 2014), os entrevistados se ancoram na produção de uma narrativa convincente e legítima de que são corpos vitimizados e autorreferidos pela desordem da desigualdade social historicamente e culturalmente construída (Fassin, 2014). Parece, desta maneira, que os entrevistados buscaram enfatizar, em suas narrativas, uma justificação da própria história de vida e da produção de documentos sobre o seu próprio corpo para adquirir reconhecimento e compaixão pelo Outro (Butler, 2015; Fassin, 2014; Honneth, 2003), desmistificando o estigma de um ser violento, um ser agressivo.

No que tange ao manto da meritocracia que consigo identificar na fala de Oswaldo, é perceptível um movimento e uma relação de causa-efeito retratada pelo entrevistado. Oswaldo relata que trabalhava em uma rotina exaustiva de muitas horas diárias e, como consequência desse sofrimento, ele "mereceu" tudo que tem. Ele conquistou, foi um vencedor, o "seu suor foi recompensado". Neste sentido, aponto a presença da ideologia liberal meritocrática presente neste trecho de fala: há a ideia de que o mérito é de Oswaldo e de mais ninguém. Foi ele quem suou, "trabalhou duro" por horas e horas e em razão disso "ganhou", “construiu” o que tem hoje. Implícito neste pensamento, também há a compreensão de que se alguém não lutar, não batalhar, a culpa é dela ou se conseguiu sem suor ou batalha, o ganho é indevido, questionável (Fonseca, 2005). Partindo dessa linha de raciocínio, entendo que Oswaldo se identifica com um ser batalhador, lutador, provedor e, em razão disso, pode exercer domínio e poder sobre as condutas "dos seus".

A partir destes trechos recortados e analisados, portanto, percebe-se que este movimento dos entrevistados se justifica pelo fato de que os entrevistados quiseram arquitetar impressões pelas quais gostariam de ser vistos, repudiado o status, lugar social ou posição (Goffman, 1981) da etiqueta de "homem autor de violência". As condutas e comportamentos discorridos nas narrativas dos entrevistados, neste sentido, pareceram revelar, além de um movimento de justificativa perante a como eu e a sociedade os 
reconhecia, os "fortes" sentidos que as concepções de "um ser violento", "um ser agressivo" possuem em nossa sociedade.

Além disso, na medida em que o "eu" se constrói pela sociedade e a sociedade é formada pelos "eus" que também deliberam valores morais e princípios éticos a depender de um contexto histórico e cultural específico, o movimento de afirmação do que o sujeito pensa sobre si, se faz justificável e condizente com a compreensão de que somos produto constantemente construído, a depender da linguagem que age socialmente sobre nós e a depender também das nossas relações sociais (Butler, 2015; Moscheta, 2014; Rasera, \& Japur, 2005).

Por fim, buscando dessencializar os marcos identitários e os estigmas que os incorporam, entendemos que o fato dos entrevistados não se reconhecerem como "agressivos" ou "violentos" ou justificarem sua agressividade e violência, fazem-nos pensar que é possível analisar a violência exercida contra as mulheres de outras maneiras, para além da dicotomia de "vítima" e "agressor". Esta compreensão, por sua vez, que visa também a responsabilização daquele que comete um ato violento, é importante para o entendimento ampliado das nuanças e pilares que sustentam a violência contra as mulheres.

\section{O relato do Outro}

Entendendo que, como seres relacionais (Gergen, 1999), performatizamos práticas morais que moldam, a partir do contato e da troca com o Outro, nosso modo de ser e estar no mundo (Gergen, 1999; Moscheta, 2014) está inerente à busca pelo reconhecimento deste Outro (Butler, 2015; Fraser, 2007; Honneth, 2003). Neste sentido, o modo como o Outro me reconhece e como eu "vejo" este Outro são nuances que, ao serem analisadas, dão suporte para o entendimento de como, neste processo, entendimentos, compreensões, estigmas, condutas, comportamentos e ações são socialmente e culturalmente construídos.

Frente às informações coletadas pelas entrevistas, os participantes relataram a forte influência do Outro em sua subjetividade e como justificativa para a ação violenta. Este pensamento pode ser representado em alguns trechos de fala. Na entrevista de Mário, por exemplo, o Outro, representado pela sogra, pelos vizinhos ou pela bebida em sua narrativa, se configurou como uma "ameaça", que fez "tudo desandar" (Entrevista Mário).
Segundo Mário, a "função" da sua sogra era a de atrapalhar e "inventar" coisas ao seu respeito, o que afetou a relação com sua ex-esposa como também, segundo Mário, culminou na separação. A respeito da bebida, Mário comenta que tanto em seu caso como no caso que discorreu em que um homem batia frequentemente em sua esposa, "Foi tudo em virtude da bebida". A bebida, nesta entrevista, pode ser entendida como um "mal", uma "ameaça", um "Outro" que leva as pessoas a cometerem delitos, violências e serem reconhecidas como pessoas violentas/agressivas. Com relação à "função" dos vizinhos, Mário relata que eram eles que falavam para seus pais sobre sua vida, criando "novidades" que faziam com que os seus pais chamassem a atenção dele. Os vizinhos, neste sentido, são vistos por Mário como seres que "atrapalharam" o diálogo de dentro de casa, fazendo ele "ficar mais bravo ainda".

A visão que o Outro tem sobre si também foi um ponto marcante discorrido por Rogério. Alinhando-se a ideia de que "ser homem" é não apresentar sensibilidade frente às situações da vida e que assumir um papel de valente e de proteção ante os seus (Núñez Noriega, 2008), Rogério, demonstra, em diversas partes, que gostaria de ser visto como um "ser que protege", "um comandante" pelos seus filhos e pela sua esposa.

Desta maneira, Rogério acredita que os Outros, especificamente, seus filhos e sua esposa, devem entendê-lo como tal. Deve, segundo ele, respeitá-lo e oferecer amor. Este amor, a saber, se conquistou a partir de suas condutas enquanto homem-macho, enquanto um homem valente e viril (Ramirez Rodríguez, \& Vázquez, 2008). Pelo "amor" conquistado, Rogério relata que consegue exercer domínio e controle ante aos seus. De acordo com o entrevistado: "Hoje eu tenho os filhos na palma da minha mão porque eu não compro. Eu não dou bolacha, eu não compro com roupa, eu não compro com nada. Eu tenho o amor. E esse amor remove todas as montanhas" (Entrevistado Rogério).

A partir desse trecho, é possível pensar a respeito da relação que o entrevistado coloca entre receber amor e exercer domínio (representado pelos dizeres: "hoje tenho os meus filhos na palma da minha mão"). O Outro aqui, parece se configurar como um serviçal, um submisso que dá a ele amor e é conivente com a figura de virilidade, dominante, "macho" e soberania que Rogério acredita ter (Con- 
nell, \& Messerschmidt, 2013; Ramirez Rodríguez, \& Vázquez, 2008).

É perceptível, a partir da leitura dos trechos destacados, que Rogério, ao se ver em uma posição de privilégio e poder, dentro de uma sociedade patriarcal (Núñez Noriega, 2008) acredita que o Outro, aqui ilustrado pela sua esposa e filhos, deve servi-lo, obedecê-lo e dar suporte para que sua dominação masculina (Bourdieu, 2007). No que se refere especificamente à figura feminina, é possível pensar também sobre este "olhar feminino" acerca deste "homem sério", deste "homem que protege". Considerando que o reconhecimento só se molda a partir do olhar do Outro, a partir da relação com o Outro (Butler, 2015), o "como" o Outro nos enxerga possui um papel importante para a concepção de si.

O "olhar feminino", neste sentido, se torna "duplamente" importante. Em primeiro lugar, por ser lapidado a partir de uma visão para além da visão de si, este olhar possui uma funcionalidade para a construção do Outro, assim como qualquer outra "visão de fora" possuiria. No entanto, este olhar, ao estar carregado do advérbio "feminino", ele possui uma especificidade diferenciada, já que o modo pelo qual a figura feminina observa/enxerga/ reconhece o homem se relaciona também a maneira como o "feminino" pode reconhecer a masculinidade deste homem (Wexler, \& Welland, 2007). Assim sendo e de acordo com Wexler e Welland (2007), muitos homens apresentam certa dependência deste reconhecimento feminino por sentir que sua masculinidade pode ser reafirmada a partir deste olhar.

A visão do Outro também pode ser entendida como uma "ameaça" nas entrevistas com os homens autores de violência. Como exemplo disso, trago o trecho da entrevista de Frederico:

E hoje pra ser agressivo, já não vale mais. Entendesse? Hoje a própria lei não deixa você ser agressivo dentro da própria família... do teu lar, entendesse? Eles já têm as formas, é, não sei... conseguir através de grupos... e... e... reuniões, e outras coisas, conselhos, né? A você, retirada, tirou de você o que tinha no passado, entendesse?

A ideia do público como uma "ameaça", como um "conjunto de condutas inadequadas" para a entidade familiar, também é possível ser identificada na fala de Mário. Para ele, os problemas familiares, antes de tudo, devem ser resolvidos "dentro de casa". Nas palavras dele, os pais foram "atrás de vizinhos", da fala de vizinhos, o que ocasionou uma série de discussões. Segundo Mário, os problemas não devem ser apontados por pessoas externas à família, nem os pais deveriam ter dado "ouvidos" aos vizinhos. Deve, de acordo com o entrevistado: "Dá um problema. Senta, conversa. O que tem pra resolver, da melhor forma. Através da discussão e briga, cada vez o problema aumenta mais" (Entrevista Mário).

Tem-se, portanto, a partir destes trechos analisados, que a linguagem e todas suas formas de performatizações possui uma representatividade nas relações sociais (Gergen, 1999). O modo como ela se apresenta, como molda narrativas, visões e olhares constroem subjetividades e se articula às dinâmicas relacionais, fazendo com que o olhar do Outro, o entendimento do Outro se constitui importante para a confecção de modos de ser e de estar no mundo. A partir dessa compreensão, portanto, entendo que a construção da subjetividade, das condutas, das ações e comportamentos se dá mediante a como o processo relacional com o Outro se constrói.

Neste sentido, as "verdades" e as visões sobre o mundo devem ser entendidas como uma produção coletiva e relacional e não individual, moldadas pelo contexto histórico, cultural e relacional (Gergen, 1999; Spink, 2010). Seguindo essa linha de pensamento, entende-se que a visão que o Outro tem de nós, a maneira como ele nos reconhece se faz um processo importante a ser analisado para ampliar o entendimento sobre a dinâmica relacional que afeta/constrói e dá lugar para que as subjetividades sejam confeccionadas. Frente a essa compreensão, entende-se também que, uma vez que as visões de mundo, os fenômenos sociais e as subjetividades são construídas socialmente e culturalmente (Gergen, 1999; Spink, 2010), entender como elas se formam, como é a compreensão do si mesmo e do Outro se faz necessário para o estudo dos fenômenos sociais, como no caso da violência contra mulheres. Isso, por sua vez, auxilia para que sejam identificados recursos e possibilidades de intervenção que objetivam a diminuição e enfrentamento da violência contra as mulheres. 


\section{Considerações finais}

Considerando que a Psicologia Social tem uma íntima relação com a transformação das condições sociais e individuais existentes (Habermas, 1987), este estudo buscou fazer uma análise sob ótica da abordagem da Psicologia Social Crítica para a produção de conhecimentos acerca das práticas narrativas produzidas pelos homens autores de violência que, de alguma forma, possuem um teor político de (re)produção de sentidos e compreensões que justificam e sustentam a violência contra as mulheres.

Dessa forma, procuramos dissertar neste texto reflexões que permitam complexificar a construção de atos de violências e suas relações com a produção de subjetividades e também provocar a própria Psicologia, em suas epistemologias, para pensar a temática. Da mesma forma, tornar visível mecanismos hegemônicos de construção discursiva de gênero e violência e a produção de questionamentos que permitam visibilizar outros caminhos e formas de subjetivar-se como homens e relacionar-se com violências.

Desejamos, neste sentido, produzir conhecimentos para subversões que apontam um sentido emancipatório social. Isso quer dizer que buscamos, a partir do estudo, propiciar um olhar crítico sobre atravessamentos que permeiam a violência contra as mulheres, levando em consideração que, assim como aponta Lane (1989), a emancipação só se faz por uma práxis crítica e criadora, e por conhecimentos que permitam evidenciar determinações obscuras e desmistificar proposições ideológicas.

Neste sentido, quisemos problematizar e questionar a respeito dos essencialismos e dicotomias que perduram em nosso tecido social e auxiliam para a elaboração de fenômenos como as violências contra as mulheres. Ao problematizar essencialismos, reconhecemos as limitações das matrizes normativas da individualidade liberal e as denunciamos (Butler, 2015). Ainda, ao fazermos isto, apontamos a importância do reconhecimento como condição para a humanidade e salientamos como a experiência de ter um gênero deve, "necessariamente, caminhar em direção a discussões mais amplas sobre como o campo da ética e da política são redimensionados quando os reconstruímos a partir do problema do reconhecimento" (Butler, 2015, p. 177).
Com este olhar, também, é possível reconhecer as possibilidades para transformação no futuro e, em especial, demonstrar que existem atores sociais e práticas sociais que contribuem para a modificação de contextos e conjunturas sociais específicas (Perea, 2003). Este movimento, também permite mostrar possibilidades diversas de relacionar-se, subjetivar-se e construir relações de gênero. Problematiza outros modos de existir como homem diante de conflitos e como o sujeito, entendido no rol de homem, dá sentido ao social, às relações que o circundam e, principalmente às condutas e comportamentos.

Aprofundando nestas questões, entendemos, ainda, que nossa sociedade construiu e constrói uma via de mão dupla para compreender a violência contra as mulheres: de um lado, a mulher vitimizada, fragilizada e impotente; do outro, um inimigo a ser eliminado, julgado e punido, que não necessariamente é capturado como sujeito efetivo da segurança pública, dado a naturalização de determinadas práticas violentas masculinas. Diante disso, perguntamos: até que ponto sustentar a dicotomia e às atribuições sociais de gênero auxilia para o enfrentamento da violência contra as mulheres? Como é mais efetivo agir: selecionar corpos para serem mais bem punidos, julgados e aprisionados pelo sistema, ou promover estratégias de responsabilização pelos atos e ruptura da dicotomia que sustenta lugares de vítima e agressor? Que psicologias são passíveis na ruptura destas dinâmicas e quais colaboram para sua manutenção? Mergulhando no entendimento dessas perguntas, tem-se, que através de mecanismos jurídicos e sociais a normatividade social é disseminada, estabelecida e justificada em prol do "bem-estar social coletivo" que, duplamente, exclui e mata as polaridades envolvidas.

Por fim, consideramos importante destacar que refletir sobre os valores éticos e morais que compõem os sentidos e justificativas da ação violenta em interface com uma Psicologia social crítica, possibilita trazer a reflexão os efeitos destes modos de vida e porque não permitimos outros. Afinal, tal como este estudo problematizou, parece haver certos comportamentos e modos de ser mais adequados para que a violência contra as mulheres não ocorra por parte de quem a comete e de quem a sofre. 


\section{Referências}

Adorno, T. W. (2001). Problems of moral philosophy (Schroder, T, Trad). Cambridge: Polity.

Beiras, A. (2008). Intervenções grupais com homens autores de violência: Um enfoque sistêmico. Disponível em: http://www.institutofamiliare.com.br/download_anexo/adriano-beiras2008.pdf

Bourdieu, P. (2007). A dominação masculina. Rio de Janeiro, RJ: Bertrand Brasil

Brasil. (2010). Ministério da Justiça e Cidadania - MJC. Secretaria de Enfrentamento à Violência contra a Mulher. Pacto nacional pelo enfrentamento à violência contra as mulheres. Brasília, DF: o autor.

Butler, J. (2003). Problemas de gênero. Rio de Janeiro, RJ: Civilização Brasileira.

Butler, J. (2015). Relatar a si mesmo: Crítica da violência ética. Belo Horizonte, MG: Autêntica.

Carneiro, A., \& Oliveira, S. (2008). Violência intrafamiliar baseada em gênero com implicação de risco de vida: Mulheres abrigadas na Casa Abrigo Maria Haydeé/ Rio Mulher/Rio de Janeiro. Encontro Nacional de Estudos Populacionais, ABEP, 16.

Connell, R.,\& Messerschmidt, J. (2013). Masculinidade hegemônica: Repensando o conceito. Revista Estudos Feministas, 21(1), 241-282. https://doi.org/10.1590/S0104-026X2013000100014

Fassin, D. (2005) L'ordre moral du monde: Essai d'anthropologie de l'intolérable. In D. Fassin, \& P. Bourdelais (Eds.), Les constructions de l'intolérable: Etudes d'anthropologie et d'histoire sur les frontières de l'espace moral (pp. 17-50). Paris: La Découverte.

Fassin, D (2014). Compassion and repression: The moral economy of immigration policies in France. Cultural Anthropology, 20(3): 362-387.

Ferreira, W. (2010). Justiça e reconhecimento em Nancy Fraser: Interpretação teórica das ações afirmativas no caso brasileiro. Perspectiva Sociológica , 5(1), 1-14.

Fonseca, C. (2005) Concepções de família e práticas de intervenção: uma contribuição antropológica. Saúde e Sociedade, 1(2), 50-59. http://dx.doi.org/10.1590/S0104-12902005000200006

Foucault, M. (1990). História da sexualidade II: O uso dos prazeres. Rio de Janeiro, RJ: Graal.

Foucault, M. (2001). Os anormais. São Paulo, SP: Martins Fontes.

Fraser, N. (2007). Reconhecimento sem ética? Lua nova, 70, 101-138.

Gergen, K. J. (1985). The social constructionist movement in modern psychology. American Psychologist, 40(3), 266-275.

Gergen, K. J. (1999). An invitation to social construction. London: Sage

Goffman, E. (1981). Forms of talk. Oxford: Basil Blackwell.

Guanaes-Lorenzi, C., Moscheta, M. S., Corradi Webster C. M., \& Souza L.V. (2014). Construcionismo social: Discurso, prática e produção do conhecimento. Rio de Janeiro, RJ: Instituto Noos.

Habermas, J. (1987). Teoria de la accion comunicativa (Vol. 2). Madrid: Catedra.

Honneth, A. (2003). Luta por reconhecimento: A gramática moral dos conflitos sociais (L. Repa, Trad.). São Paulo, SP: Ed. 34 .

Lane, S. T. M. (1989). A psicologia social e uma nova concepção do homem para a Psicologia. In s. t. m., Lane, \&W. Codo (Orgs.), Psicologia social: O homem em movimento (8a ed., pp. 10-19). São Paulo, SP: Brasiliense.

Martins, P. P. S., McNamee, S., \& Guanaes-Lorenzi, C. (2014). Family as a discursive achievement: A relational account. Marriage \& Family Review, 50(7), 621-637. https://doi.org/10.1080/01494929.2014.938290

Moscheta, M. S. (2014). A pós-modernidade e o contexto para a emergência do discurso construcionista social In C. Guanaes-Lorenzi, M. S. Moscheta, C. M. Corradi-Webster, \& L. V. Souza, Construcionismo social: Discurso, prática e produção do conhecimento (pp 23- 47). Rio de Janeiro, RJ: Instituto Noos.

Motta, N. S. (1984). Ética e vida profissional. Rio de Janeiro, RJ: Âmbito Cultural 
Núñez Noriega, G. (2008). Los "hombres" en los estudios de género de los "hombres": Un reto desde los estudios queer. In J. C. Ramirez Rodriguez, \& G. Uribe Vásquez (Orgs), Masculinidades: El juego de género de los hombres en el que participan las mujeres (pp. 43-57). Madrid: Plaza y valdés,

Pedro, A. P (2014). Ética, moral, axiologia e valores: confusões e ambiguidades em torno de um conceito comum. Kriterion: Revista de Filosofia, 55(130), 438-498. https://doi.org/10.1590/S0100-512X2014000200002

Perea, J. G. F (2003). La evaluación ética de proyectos de investigación desde una perspectiva de género. Revista Mexicana de Bioética, 1(1), 65-77.

Rasera, E. F., \& Japur, M. (2005). Os sentidos da construção social: o convite construcionista para a Psicologia. Paidéia (Ribeirão Preto), 15(30), 21-29. https://doi.org/10.1590/S0103-863X2005000100005

Ramirez Rodríguez, J. C. \& Vázquez, G. (Eds.). (2008). Masculinidades: El juego de género de los hombres en el que participan las mujeres. Madrid: Plaza y Valdés.

Spink, M. J. (2010). Psicologia social e saúde: Trabalhando com a complexidade. Quaderns de Psicología, 12, 41-56

Villela, W. V., \& Lago, T. (2007). Conquistas e desafios no atendimento das mulheres que sofreram violência sexual. Cadernos de Saúde Pública, 23(2), 471-475. https://doi.org/10.1590/S0102-311X2007000200025.

Wexler, D., \&Welland, C. (2007). Sin golpes: Cómo transformer la respuesta violenta de los hombres en la pareja y la familia. México, DF: Pax México.

\section{Ana Luíza Casasanta Garcia}

Doutoranda do Programa de Pós-Graduação Interdisciplinar em Ciências Humanas da Universidade Federal de Santa Catarina, Florianópolis - SC. Brasil.

E-mail: analuizagarcia@hotmail.com

(iD) https://orcid.org/0000-0002-3947-273X

\section{Adriano Beiras}

Professor do Programa de Pós-graduação e do Departamento de Psicologia da Universidade Federal de Santa Catarina, Florianópolis - SC. Brasil.

E-mail: adrianobe@gmail.com

(iD https:// orcid.org/0000-0002-1388-9326

Endereço para envio de correspondência:

Universidade Federal de Santa Catarina, Departamento de Psicologia. Rua Eng. Agronômico Andrei Cristian Ferreira, s/n - Trindade, CEP: 88040-900. Florianópolis - SC. Brasil.

Recebido:26/06/2019

Aceito: 22/07/2019

Received:06/26/2019

Approved: 07/22/2019

Recibido:26/06/2019

Aceptado: 22/07/2019 
Como citar: Garcia, A. L. C., \& Beiras, A. (2019). A Psicologia Social no estudo de justificativas e narrativas de homens autores de violência. Psicologia: Ciência e Profissão, 39(n.spe 2), 45-58. https://doi.org/10.1590/1982-3703003225647

How to cite: Garcia, A. L. C., \& Beiras, A. (2019). Social Psychology in the study of justifications and narratives of men who commit violence. Psicologia: Ciência e Profissão, 39(n.spe 2), 45-58. https://doi.org/10.1590/1982-3703003225647

Cómo citar: Garcia, A. L. C., \& Beiras, A. (2019). La Psicología Social en el estudio de justificativas y narrativas de hombres autores de violencia. Psicologia: Ciência e Profissão, 39(n.spe 2), 45-58. https://doi.org/10.1590/1982-3703003225647 